\section{A produção do conhecimento da saúde pública sobre a relação homem-saúde: uma revisão bibliográfica}

\author{
Public health research output related to males \\ and health: a bibliographical review
}

\author{
1 Instituto Fernandes \\ Figueira, Fundação Oswaldo \\ Cruz, Rio de Janeiro, Brasil. \\ Correspondência \\ R. Gomes \\ Departamento de Ensino, \\ Instituto Fernandes Figueira \\ Fundação Oswaldo Cruz. \\ Av. Rui Barbosa 716, \\ Rio de Janeiro, $R J$ \\ 22250-020, Brasil. \\ romeu@iff.fiocruz.br
}

\section{Abstract}

This study focuses on the research output in the relationship between males and health in the public health field. The objective is to critically analyze the most recurrent ideas on the specificities of maleness in the health-disease process. The method consisted of a literature review in public health, based on a qualitative research approach. Male sexuality, masculinity, and reproduction and masculinity and power were the themes found in the analysis. The study concludes that further research on masculinity is needed with a focus on gender, nationality, class, age, ethnicity, and sexual orientation.

Men's Health; Review Literature; Qualitative Research
Romeu Gomes 1

Elaine Ferreira do Nascimento 1

\section{Introdução}

A década de 70 do século passado é considerada como o marco dos estudos norte-americanos acerca da temática "homem e saúde". Esses estudos traduziam um pensamento exploratório tangenciado pela teoria e política feministas e conceitualmente pressupunham que a masculinidade tradicional produzia déficit de saúde 1,2 .

A partir dos anos 90 do século XX, a temática em questão começou a ser abordada sob uma perspectiva diferenciada. A discussão passou a refletir, dentre outros aspectos, a singularidade do ser saudável e do ser doente entre segmentos masculinos. Essa abordagem, sem perder a perspectiva relacional de gênero, veio focalizando, sobretudo, a ressignificação do masculino para buscar-se uma saúde mais integral do homem 2 . A exemplo disso, destacamse publicações da Organização Mundial da Saúde (OMS) 3,4 que se voltam para as especificidades da saúde masculina ou o seu comprometimento em diferentes fases da vida.

Na primeira publicação ${ }^{3}$, defende-se uma abordagem específica para os rapazes nas ações da área da saúde, porque as principais causas da mortalidade de homens, em geral, relacionam-se com a forma de sua socialização e suas formas de vida. Por outro lado, também se pontua que os comportamentos dos homens adolescentes e adultos podem ser res- 
ponsáveis por grande parte das morbidades sofridas por mulheres adolescentes.

A segunda publicação da OMS 4 se propõe a estabelecer uma base para que políticas e estratégias voltadas para os homens em processo de envelhecimento sejam desenvolvidas. O documento endossa a pertinência das abordagens de gênero específicas que costumam identificar as desigualdades persistentes no status que as mulheres ocupam nas sociedades. Também alerta para o fato de que há uma necessidade de promover-se investigações e estudos em geral acerca da posição social específica dos homens, especialmente os mais velhos, e as repercussões em termos de determinantes da saúde masculina.

A perspectiva relacional de gênero perpassando as discussões a respeito da saúde do homem é um dos eixos estruturantes dessas publicações.

A criação de uma sociedade internacional voltada para a saúde dos homens e gênero (International Society for Men's Health and Gender - ISMH) e de um periódico específico sobre esse assunto Uournal of Men's Health and Gender) também podem ilustrar o interesse crescente que vem ocorrendo na área da saúde em relação às especificidades a serem levadas em conta na abordagem da saúde masculina 5 .

$\mathrm{Na}$ literatura internacional, quando se busca refletir acerca da temática "homem e saúde", algumas considerações fundamentais se destacam. Essas considerações - que não se excluem mutuamente - podem ser resumidas da seguinte forma: (a) os homens, em geral, padecem mais de condições severas e crônicas de saúde do que as mulheres e também morrem mais do que elas pelas principais causas de morte 1,2,6; (b) há uma relação entre a construção da masculinidade e o comprometimento da saúde dos homens 1,2,3,7,8; (c) tanto a construção da masculinidade quanto as suas implicações no campo da saúde devem ser vistas a partir da perspectiva relacional de gênero $1,3,7,8$; (d) o desenvolvimento de habilidades agressivas por parte dos homens 7 pode fazer deles um "fator de risco" quando cometem violência contra a mulher e as crianças (principalmente por meio de abusos e a paternidade ausente), contra os outros homens (através de acidentes, homicídios e lesões) e contra eles mesmos (mediante o suicídio, alcoolismo, assim como as enfermidades psicossomáticas) 8; (e) devido à centralidade que o trabalho ocupa na identidade do homem como ser provedor, problemas relacionados ao desemprego podem também comprometer o bem-estar masculino 6,8 e contribuir para o aumento de suicídios de jovens 6 .
As considerações apontadas pela literatura podem servir como ponto de partida para o desenvolvimento de estudos específicos sobre diferentes segmentos masculinos, a formulação de políticas de saúde voltadas para as relações de gênero e o desenvolvimento de ações de saúde em geral. Como base nessa premissa, surge a necessidade de investigar-se qual é o estado da arte da produção científica do campo da saúde pública para que se possa fundamentar uma abordagem específica para a saúde integral do homem nas relações de gênero.

A partir dessa perspectiva, o presente estudo tem como objetivo analisar a produção do conhecimento da saúde pública sobre a temática "homem e saúde". Pretende-se, a partir dessa análise, problematizar as idéias mais recorrentes nas considerações sobre as especificidades do ser homem no processo saúde-doença.

\section{Material e método}

Há inúmeros caminhos para refletir-se sobre a produção de um conhecimento de uma área. Neste estudo, a opção foi por uma revisão bibliográfica, realizada a partir de uma abordagem de pesquisa qualitativa.

Em termos de tipo de fonte de pesquisa, trabalhou-se com artigo científico publicado em periódicos da saúde pública. Essa modalidade de produção, além de ser comumente a mais valorizada no conjunto da produção bibliográfica, é a mais facilmente acessada.

$\mathrm{O}$ acesso aos artigos foi através da biblioteca virtual SciELO (http//www.scielo.org). Nessa biblioteca, consta uma seção específica para a saúde pública, com oito periódicos, com textos de artigos disponibilizados na íntegra. Os periódicos que constam nessa seção são os seguintes: Bulletin of the World Health Organization, Cadernos de Saúde Pública, Gaceta Sanitária, Revista de Salud Pública, Revista de Saúde Pública, Revista Española de Salud Pública, Revista Panamericana Salud Pública e Salud Pública de México. Considerar apenas essa seção consiste num limite do estudo, uma vez que artigos pertencentes a periódicos que integram outras secções da referida biblioteca eletrônica poderiam também contribuir para a discussão da produção do conhecimento sobre a relação homem-saúde. No entanto, em princípio, no interior desses artigos, necessariamente, poderia não haver uma discussão voltada para a saúde pública, uma vez que não integram a seção específica dessa área.

O primeiro acesso aos artigos foi em $18 \mathrm{de}$ maio de 2004, com os seguintes assuntos: ho- 
mem, masculinidade, masculino, saúde do homem, saúde masculina e as expressões equivalentes a esses assuntos nas línguas inglesa e espanhola. Em 18 de abril de 2005, foi feito outro acesso para completar todos os artigos publicados em 2004. O artigo mais antigo encontrado sobre o assunto nessa biblioteca foi publicado em 1998. Assim, o período estudado foi de 1998 a 2004. Dos oito periódicos, seis continham artigos com os assuntos da busca. Ao todo, foram identificados 36 artigos.

A análise dos artigos foi predominantemente de cunho qualitativo, ou seja: ao invés de chegar-se aos temas pela utilização de medidas, procurou-se interpretar os sentidos das idéias centrais dos artigos. No entanto, antes de chegar-se à análise qualitativa dos artigos, foi realizada uma caracterização do conjunto da produção a partir de freqüências. Tal caracterização serviu apenas de cenário da análise propriamente dita.

A análise qualitativa dos conteúdos dos artigos foi realizada a partir de uma adaptação da técnica de análise de conteúdo, modalidade temática, descrita por Bardin 9. Para essa autora, o tema é uma unidade de significação que se liberta do texto analisado e pode ser traduzido por um resumo, por uma frase ou por uma palavra. Ainda para a autora, para chegar-se ao tema, faz-se necessário "descobrir os 'núcleos de sentido' que compõem a comunicação e cuja presença, ou freqüência de aparição, podem significar alguma coisa para o objetivo analítico escolhido" 9 (p. 105). Com essa técnica, pode-se caminhar, também, na direção da "descoberta do que está por trás dos conteúdos manifestos, indo além das aparências do que está sendo analisado" 10 (p. 74).

$\mathrm{Na}$ análise temática de Bardin ${ }^{9}$, o núcleo de sentido e tema integram um mesmo processo analítico, sendo o primeiro o ponto de partida para estabelecer-se o segundo. Nesta revisão bibliográfica, o tema está sendo entendido como uma categoria mais ampla que pode abranger mais de um núcleo de sentido.

$\mathrm{Na}$ análise dos artigos, caminhou-se da identificação das idéias centrais dos artigos, passando pela interpretação dos sentidos dessas idéias e pelo agrupamento das idéias em categorias empíricas ou núcleos de sentido, chegando-se a descrição de temas, como classificações mais amplas.

Em síntese, basicamente, foram percorridos os seguintes passos de análise: (a) leitura exaustiva de cada artigo visando a uma compreensão global e à descoberta da abordagem utilizada pelos seus autores; (b) identificação das idéias centrais de cada artigo; (b) classifi- cação das idéias em torno de núcleos de sentido; (c) comparação entre os diferentes núcleos de sentido presentes nos artigos estudados; (d) classificação dos núcleos de sentido em eixos mais abrangentes (temas) em torno dos quais giravam as discussões dos autores e (e) redação das sínteses interpretativas de cada tema.

Após a análise dos conteúdos dos artigos, buscou-se estabelecer um diálogo entre as temáticas encontradas e a literatura $1,2,3,4,5,6,7,8$ que serviu de base para introduzir o presente estudo.

\section{Caracterização das fontes de análise}

Com base nos títulos dos artigos, verificou-se que, em termos dos três primeiros assuntos mais freqüentes, as doenças sexualmente transmissíveis (DST), incluindo a AIDS, foi o assunto mais focalizado ao tratar-se do sexo masculino, representando $42 \%$ dos artigos, seguido por assuntos relacionados à reprodução (25\%) e violência (8\%).

A partir desses dados, observa-se que problemas a serem enfrentados pela saúde pública, como é o caso da AIDS e da violência cometida contra a mulher, demandam uma discussão específica das questões masculinas, inseridas nas relações de gênero. Esses artigos, de certa forma, podem vir ao encontro dessas demandas.

Constatou-se também que uma das áreas que mais vem desenvolvendo discussões sobre questões relacionadas à masculinidade é a saúde reprodutiva. Essa constatação reforça a idéia de que essa área é considerada como o campo que mais vem advogando a participação dos homens nas ações de saúde 8 .

Ainda em termos de caracterização das fontes, como pode ser observado na Tabela 1, a maioria dos artigos possui método quantitativo. Em geral, são estudos transversais, desenvolvidos a partir de uma perspectiva epidemiológica.

Por último, observa-se que os estudos de Leyva-Lopez et al. 11, Pépin et al. 12 e Monteiro et al. 13 foram retirados da análise por não trazerem uma discussão específica sobre homem ou masculinidade. Os dois primeiros se baseavam em pesquisas clínicas exclusivamente sobre doenças relacionadas à uretra masculina, $\mathrm{e}$ o terceiro apenas recomendava que fossem desenvolvidas mais pesquisas que trabalhassem a relação entre obesidade e homem. 
Distribuição das referências estudadas por tipo de método.

\begin{tabular}{|c|c|c|}
\hline Método & Referências & n \\
\hline Qualitativo & Guerriero et al. 20; Rios 21; Silva 29; Stern et al. 22; Villaseñor-Farias \& Castañeda-Torres 43; Viveros et al. 34. & 6 \\
\hline Quantitativo & $\begin{array}{l}\text { Abrahams et al. 45; Antunes et al. 35; Berhame et al. 46; Burattini et al. 23; Cañellas et al. 30; Castellsagué et al. } 15 ; \\
\text { Cruz-Peñarán 36; Duarte et al. 38; Espírito-Santo \& Etheredge 16; Hawkes et al. 17; Hernández-Giron et al. 31; } \\
\text { Hindin 44; Izazola-Licea et al. 24; Leyva-Lopez et al. 11; Mariño et al. 28; Nieto-Andrade \& Izazola-Licea 18; } \\
\text { Pépin et al. 12, Secretaría del Plan Nacional sobre Sida/Programas de Sida de las Comunidades Autónomas/ } \\
\text { Red de Centros de Enfermedades de Transmisión Sexual, VIH y Planificación Familiar 19; Vilarinho et al. 32; } \\
\text { Viliet et al. 27. }\end{array}$ & 20 \\
\hline Quali-quantitativo & Carvalho et al. 37 ; Vieira et al. 33. & 2 \\
\hline Revisão & $\begin{array}{l}\text { Figueroa-Perea 25; Funari 26; Golden et al. 39; Jarrel 42; Monteiro et al. 13; Multigner \& Oliva 40; O’Farrell 15; } \\
\text { Rittler \& Castilla 41. }\end{array}$ & 8 \\
\hline Total & & 36 \\
\hline
\end{tabular}

\section{Temas da produção estudada}

A partir das idéias centrais dos artigos e do agrupamento dessas idéias em torno de núcleos de sentido, chegou-se a três temas que podem sintetizar a produção estudada: sexualidade masculina, masculinidade e reprodução e masculinidade e poder. Tais temas, embora possam ser entendidos como classificações que estruturam a discussão, necessariamente, não seguem o princípio de exclusão mútua. Eles são apenas prismas da discussão dos sentidos atribuídos às idéias que, em determinados momentos, podem superpor-se.

\section{Sexualidade masculina}

O tema sexualidade masculina é o foco central no conjunto das fontes estudadas, estando presente nesse conjunto de uma forma implícita ou explícita. Essa sexualidade, para os trabalhos revisados, deve ser debatida para que se possam abordar assuntos como as DST e a AIDS. Esse debate, segundo um dos autores estudados 14 , torna-se um grande desafio para a saúde pública por causa das interdições culturais que a ela atravessam.

O tema da sexualidade masculina se traduz pelos seguintes núcleos de sentido: sexualidade infectante, heterossexualidade e sexualidade não-monogâmica.

O primeiro núcleo de sentido da sexualidade masculina se refere à sua característica infectante. Essa característica pode ser inferida a partir, principalmente, dos seguintes autores revisados: O'Farrel 14; Catellsagué et al. 15; Espírito-Santo \& Etheredge 16; Hawkes et al. 17 e Nieto-Andrade \& Izazola-Licea 18.

A associação entre sexualidade masculina e infecção ocorre principalmente a partir do fato de haver uma superior participação masculina em relação à feminina nos perfis epidemiológicos das DST. O’Farrel 14 (p. 575), por exemplo, concluiu que, nos "países mais afetados pelo HIV, as proporções de homens e mulheres com IST que apresentam úlceras genitais eram, respectivamente, de 45\%-68\% e de 13\%$68 \% "$. Outro estudo 19 , numa rede de centros de atendimento de DST/HIV e planejamento familiar da Espanha, constatou que a soroprevalência do HIV foi maior em homens $(5,9 \%)$ do que em mulheres $(2,6 \%)$.

Catellsagué et al. 15 verificaram que, em relação ao papilomavírus humanos (HPV) genitais (que são predominantemente sexualmente transmitidos), o risco de câncer cervical, em uma mulher, pode depender menos de sua conduta sexual do que a de seu marido ou de outros companheiros. Esses autores também concluíram que, em relação a fatores de proteção a doenças, homens circuncidados tinham três vezes menos chances para abrigar o HPV em seu pênis do que homens não circuncidados.

Mesmo nos trabalhos analisados em que se detectou uma baixa prevalência de infecções por HIV, observou-se que, entre os homens, havia um nível alto de comportamento de risco reportado e um nível baixo de proteção 17 . Segundo Nieto-Andrade \& Izazola-Licea 18 , numa amostra de 8.068 homens mexicanos, as va- 
riáveis que mediram conhecimento sobre a AIDS e seus mecanismos de transmissão e prevenção (variável independente) não tiveram uma relação estatisticamente significativa $(\mathrm{p}<$ $0,05)$ com o fato de ter usado preservativo na última relação sexual vaginal com uma parceira estável (variável dependente). Isso sugere que as medidas preventivas nem sempre dependem do conhecimento sobre as formas de prevenir-se.

A sexualidade masculina vista como infectante também se expressa pela relação dos homens com a prostituição. Espírito-Santo \& Etheredge 16 encontraram uma prevalência de $4,4 \%$ de testes positivos de HIV entre clientes de trabalhadoras do sexo no Senegal.

No que se refere ao segundo núcleo de sentido, observa-se que a heterossexualidade estrutura a sexualidade masculina. Esse sentido se revela, principalmente, nos seguintes autores revisados: O'Farrel 14; Guerriero et al. 20; Rios 21; Stern et al. 22; Burattini et al. 23; IzazolaLicea et al. 24; Figueroa-Perea 25 e Funari 26.

Segundo Stern et al. 22, em geral, a iniciação sexual dos homens, que costuma ocorrer durante a transição entre ser criança e ser adulto, é marcada pela necessidade de afirmar a sua heterossexualidade. Figueroa-Perea 25 observa que, no cenário do estereótipo da sexualidade erótica masculina, essa necessidade pode ser tão acirrada a ponto de homens expressarem uma homofobia para não serem identificados como "homossexual".

Vários autores revisados 14,20,24 concluíram que a concepção de que a heterossexualidade é característica exclusiva de ser homem pode constituir-se num problema para as investigações relacionadas à AIDS. Devido ao domínio dessa característica na sexualidade masculina, o sexo vaginal assume um status de "normalidade", e a AIDS é vista como uma doença associada a comportamentos "anormais", como a homossexualidade, e isso, por conseqüência, pode distanciar os homens, em geral, das pesquisas sobre essa infecção 20 . Viliet et al. 27, ao contrário, mostram que mais de $90 \%$ dos casos adultos de HIV/AIDS, em países africanos e asiáticos, são atribuídos a atividades heterossexuais.

A associação entre AIDS e homossexualidade se encontra epidemiologicamente sustentada pelos autores estudados. Funari 26, por exemplo, baseado em dados do Ministério da Saúde, verificou que, no Brasil, no período 1990/1999, 48\% dos casos de transmissão do HIV/AIDS por via sexual estiveram relacionados a contatos de homens que fazem sexo com homens.
Embora a heterossexualidade seja a norma da sexualidade masculina, há situações, como mostram alguns artigos analisados $21,23,28$, em que as práticas homossexuais podem ser toleradas, não comprometendo o ser masculino. Tais situações podem ser exemplificadas com: (a) as interações eróticas temporárias ocorridas na infância, em parcerias interetárias e intergeracionais 21 ; (b) as relações sexuais praticadas entre homens em populações carcerárias 23 e (c) as relações sexuais comerciais praticadas por trabalhadores masculinos do sexo mantidas com homens.

O terceiro núcleo de sentido presente no tema relacionado à sexualidade masculina é o da não-monogamia. Essa discussão se sustenta, principalmente, a partir dos seguintes autores revisados: Guerriero et al. 20; Silva 29; Cañellas et al. 30; Hawkes et al. 17; Hernández-Girón et al. 31; Nieto-Andrade \& Izazola-Licea 18; Villarinho et al. 32 e Vieira et al. 33 .

Nos estudos desenvolvidos por esses autores, está implícito que o exercício da sexualidade masculina pode ocorrer com múltiplas e simultâneas parceiras sexuais. Esse exercício nem sempre é declarado por causa do discurso hegemônico de que as relações sexuais devem ser regidas pela monogamia. Esse pensamento hegemônico traz como conseqüência a idéia de que fidelidade deve existir entre os parceiros. Isso, de uma certa forma, pode comprometer o uso de preservativos nas relações heterossexuais entre parceiros estáveis 18,31.

Cañellas et al. 30 observam que a fidelidade presumida para parceiros estáveis não se reduz às relações heterossexuais. Segundo esses autores, as relações homossexuais entre parceiros estáveis também costumam seguir essa lógica, fazendo com que, nessas relações, o preservativo comumente não seja utilizado.

Os autores estudados chamam a atenção para o fato de a fidelidade ser uma norma comumente cobrada apenas das mulheres 17,20,29,32. Seguindo esse raciocínio, Guerriero et al. ${ }^{20}$ verificaram que, entre um grupo de motoristas de ônibus da Cidade de São Paulo, estava presente a idéia da infidelidade masculina, uma vez que, segundo os motoristas estudados, o homem tem mais necessidade de sexo do que a mulher, revelando um desejo incontrolável. Ainda para esses autores, a fidelidade masculina pode ser vista como algo que compromete a imagem de ser homem, porque pode ser entendida como a perda do interesse sexual. Já a infidelidade feminina pode ser vista como um sinal da deficiência do parceiro.

Os autores analisados - que trazem esse debate - observam que a fidelidade masculi- 
na se reduz ao respeito pela parceira, e o uso de preservativo só é previsto nas relações extraconjugais, que podem apresentar o risco de infecções.

Especificamente sobre o uso de preservativo masculino, Vieira et al. 33 constataram, numa amostra de 597 homens, na Cidade de São Paulo, que $18 \%$ dos sujeitos sem parceiras disseram estar habituados a usar o preservativo; $38 \%$ relataram que não faziam tal uso; $13 \%$ utilizavam ocasionalmente com a sua parceira ou outra mulher; $17 \%$ faziam uso em relações extraconjugais e $13 \%$ reportaram o uso com a sua parceira.

Ampliando a discussão sobre a monogamia, Villarinho et al. 32 (p. 65) concluíram que "ainda prevalece a crença de que apenas o homem busca relações extraconjugais, enquanto a mulher (a sua) permanece na relação matrimonial (...) Esse risco é colocado no outro, na companheira, não em seu próprio comportamento". Nesse sentido, quando os homens buscam relações rápidas ou com pessoas envolvidas na prostituição, por exemplo, podem até usar preservativo. Isso pode ser explicado pelo fato de que deve haver cuidados com um parceiro pouco conhecido ou proveniente de um "grupo de risco”. Assim, nas relações sexuais estáveis, não se costuma usar o preservativo por pressupor-se a existência da monogamia. Admitir tal uso no interior dessas relações significa assumir a infidelidade, valor oficialmente combatido.

\section{Masculinidade e reprodução}

A análise das fontes bibliográficas revela que as relações estabelecidas entre masculinidade $e$ reprodução podem ser traduzidas a partir dos seguintes núcleos de sentido: a pouca participação masculina, insuficiência das informações e comprometimentos da reprodução masculina.

A pouca participação masculina nas questões relacionadas à saúde reprodutiva, mais especificamente na discussão sobre a contracepção, é uma constatação nos seguintes autores revisados: Stern et al. 22; Viveros et al. 34; Antunes et al. 35; Cruz-Peñarán et al. 36; Carvalho et al. 37 e Figueroa-Perea 25 .

Carvalho et al. 37 concluíram que a pouca participação masculina revela que comumente se atribui à mulher a responsabilidade pela adoção de métodos contraceptivos. Esses autores verificaram que, numa amostra de 254 mulheres da Cidade de São Paulo, apenas 19\% referiram que havia o uso rotineiro de métodos masculinos na sua relação com seus parceiros, visando à contracepção. Ainda segundo esses autores, em termos dos três principais métodos anticoncepcionais, a pílula anticoncepcional foi o mais utilizado $(67,3 \%)$, seguido pelo uso do preservativo $(10,2 \%)$ e o coito interrompido $(6,7 \%)$.

Antunes et al. 35, numa amostra de 394 jovens estudantes do Município de São Paulo, verificaram que as próprias mulheres conversavam mais com os amigos sobre os métodos contraceptivos $(67 \%)$ do que os homens (43\%).

A esterilização também foi apontada como um exemplo que pode reforçar a pouca participação masculina na contracepção. Segundo Viveros et al. 34 , em um estudo com profissionais e usuários de um serviço de vasectomia de Bogotá, na Colômbia, embora tenha havido um aumento da esterilização masculina, esta representava apenas $5 \%$ em relação ao total das esterilizações de ambos os sexos. Esses autores sugerem que, para conseguir-se um maior envolvimento dos homens na utilização da esterilização como medida contraceptiva, faz-se necessário atribuir à vasectomia um significado positivo, desassociando-a da idéia de que ela pode comprometer a sexualidade masculina. Para eles, faz-se necessário também criticar a associação entre vasectomia e castração.

Ampliando a discussão sobre a pouca participação masculina no uso de métodos anticoncepcionais, observou-se que essa questão pode está relacionada com a existência de tipos desses métodos. Cruz-Penãrán et al. 36 , com base em estudo com 600 casais da selva peruana, argumentam que há mais medidas anticoncepcionais para mulheres do que para homens, e essa realidade pode contribuir para que a população masculina perceba a mulher como a responsável por tais medidas.

Para Carvalho et al. ${ }^{37}$, embora se tenha constatado que nem sempre há uma correlação entre a participação masculina e o uso de métodos contraceptivos masculinos, defendese o envolvimento dos homens no planejamento familiar em geral e a sua participação na contracepção em específico. Esses autores concluíram que a participação do homem poderia significar apenas apoio (permissão para a sua parceira usar métodos contraceptivos e ações de comprar a pílula anticoncepcional, lembrar a mulher de tomar tal pílula e opinar sobre o número de filhos desejados) e uso de método masculino (preservativo, abstinência sexual, coito interrompido, uso de tabela).

Ainda sobre a participação masculina nas questões de saúde reprodutiva, Figueroa-Perea 25 considera ser necessário incorporar os homens numa perspectiva real, simbólica e científica nos processos relacionais de saúde, se- 
xualidade e reprodução. Para o autor, através dessa incorporação, pode-se apreender e reconhecer as necessidades e decodificar a história de desigualdades de gênero com vistas a gerar um cuidado coletivo, construir novos discursos e um reencontro de subjetividades.

O segundo núcleo de sentido se refere à insuficiência de informações sobre a contracepção e a reprodução. Essa discussão se encontra desenvolvida, principalmente, nos seguintes autores revisados: Stern et al. 22; Cruz-Peñarán et al. 36 e Duarte et al. 38 .

Stern et al. 22, baseados em oito grupos focais e 18 entrevistas individuais com jovens da Cidade do México, concluíram que os rapazes estão pouco e, em muitas ocasiões, mal informados sobre questões reprodutivas, e falar sobre medidas protetoras com suas amigas e parceiras sexuais pode lhes causar ansiedade.

Em geral, os autores revisados que tratam da insuficiência de informações no campo da saúde reprodutiva fazem considerações sobre níveis escolares. Cruz-Peñarán et al. 36, por exemplo, verificaram que a educação pode afetar, indiretamente, o planejamento familiar, uma vez que a menor escolaridade dos seus sujeitos se associou a uma atitude menos favorável a esse planejamento.

A escolaridade não só influencia a contracepção como a interrupção da gestação indesejada ou não planejada. Duarte et al. 38 , com base num estudo com 910 sujeitos, em universidade de Campinas (São Paulo, Brasil), verificaram que o maior grau de escolaridade, tanto dos homens quanto das mulheres, foi um dos fatores para determinar a perspectiva dos sujeitos sobre a possibilidade de interrupção da gestação.

O terceiro núcleo de sentido relacionado à saúde reprodutiva é o comprometimento da reprodução masculina. Isso se sustenta, principalmente, a partir das discussões de Golden et al. 39, Multigner \& Oliva 40 e Rittler \& Castilla 41. Golden et al. 39 destacam que um dos indicadores desse comprometimento são as estimativas norte-americanas e da OMS de que, em pelo menos $50 \%$ dos casais infecundos, o "fator masculino" está presente, e que $30 \%$ podem ser causados por um "fator puramente masculino".

No conjunto das fontes estudadas, ressaltam-se as seguintes conclusões sobre os comprometimentos da reprodução masculina: (a) há estudos internacionais do final do século XX que relatam a diminuição significativa na concentração de espermatozóides, e esse declínio pode estar associado à poluição industrial e agrícola e pode aumentar o número de casais infecundos 40; (b) estudos publicados em 1938 e 1990 sugerem um declínio na concentração de esperma e no volume do sêmen 41; (c) há uma preocupação crescente no sentido de que as exposições ambientais a diversos produtos químicos atuem contra a reprodução masculina 39,42 .

\section{Masculinidade e poder}

No conjunto dos artigos revisados, o tema masculinidade e poder não é aprofundado em termos da centralidade do poder como eixo estruturante da construção do masculino. Entretanto, nesse conjunto, são tecidas considerações sobre os efeitos desse poder no trato das questões de saúde pública.

A discussão sobre as relações entre masculinidade e poder pode ser traduzida a partir dos seguintes núcleos de sentido: violência masculina, invencibilidade masculina e homem como ser provedor.

O núcleo de sentido violência masculina surge na discussão de autores revisados, como: Villaseñor-Farias \& Castañeda-Torres 43 e Hindin 44. Para Villaseñor-Farias \& Castañeda-Torres 43 , baseados em estudo que envolveu 155 adolescentes em Guadalajara, no México, o exercício da violência se configura como característica masculina e masculinizadora. Nesse contexto, a violência é percebida como uma forma social de poder, constituindo-se numa estratégia de empoderamento.

Nos estudos de Abrahams et al. 45 e Villaseñor-Farias \& Castañeda-Torres 43 , a violência sexual é considerada uma das formas violentas mais utilizadas por homens. Sobre esse tipo de violência, Abrahams et al. 45 , baseado num estudo com 1.368 homens da Cidade do Cabo (África do Sul), concluíram que só havia dois tipos de conflitos significativamente associados à violência sexual: (a) aqueles derivados da recusa sexual por parte de suas parceiras e (b) os derivados de desavenças conjugais que surgiam quando os homens percebiam que a sua autoridade estava ameaçada.

Segundo Hindin 44, com base em um estudo realizado em Zimbawe com 5.907 mulheres, a violência masculina cometida contra a mulher pode ser "naturalizada" pelas próprias mulheres. O autor concluiu que mais da metade de todas as mulheres estudadas (53\%) acreditavam que o maltrato cometido contra esposas poderia ser justificado nas seguintes situações: quando a esposa havia discutido com seu cônjuge (36\%), não atendia a seus filhos (33\%) ou saía de casa sem dizer ao marido aonde ia (30\%). Para esse autor, as mulheres que declararam que tomavam as decisões domésticas conjuntamente com seu parceiro demonstra- 
ram uma menor tendência a justificar o maltrato conjugal.

O referido autor apresenta ainda dados internacionais, apontando para a magnitude e o significado da violência masculina contra as mulheres: (a) estimativas de vários países indicam que, entre pessoas de 15 a 44 anos de idade, a violência do homem contra a sua companheira é a terceira principal causa de morte de mulheres; (b) na América Latina, há constatações de que entre $8 \%$ a $32 \%$ de homens e mulheres consideram que o maltrato cometido contra a companheira é justificado em casos de suspeita de infidelidade; (c) a compreensão das causas dessa violência requer, dentre outros aspectos, uma análise do contexto social no qual ela ocorre, incluindo-se, nesse contexto, o papel da mulher, as normas de gênero, status sócio-econômico e a dinâmica das relações; (d) entre as principais razões para aceitar-se os maus-tratos cometidos contra esposas, encontra-se a recusa por parte delas em ter relações sexuais com seus companheiros e a negligência cometida contra as crianças; (e) a violência doméstica tem sido aceita ou reforçada por conta de normas de gênero e valores que situam a mulher numa posição de subordinação ao homem.

O núcleo de sentido invencibilidade masculina do tema masculinidade e poder se caracteriza por concepções dominantes de ser homem, nas quais - dentre as inúmeras imagens associadas à masculinidade - destacamse as de ser forte, ter corpo resistente e ser invulnerável. Essas imagens podem decorrer da naturalização do poder masculino. No conjunto das fontes revisadas, essas discussões estão presentes, principalmente, nos trabalhos de Guerriero et al. 20, Stern et al. 22 e FigueroaPerea 25

Segundo Stern et al. 22, para adolescentes mexicanos, dentro do modelo dominante de masculinidade, destaca-se que ser homem é ser forte. Figueroa-Perea 25, com base em estudos brasileiros, observa que, na construção e na percepção social do corpo masculino, ressalta-se a idéia de ser resistente. Essa idéia pode fazer com que homens caracterizem as suas vidas como algo heróico. Guerriero et al. 20, baseado em entrevistas com motoristas paulistanos, o fato de homens se sentirem fortes pode fazer com que os tornem mais vulneráveis a riscos e doenças.

Esses autores trazem uma discussão importante quando discutem as implicações de modelos dominantes de masculinidade para o campo da saúde pública. Dentre eles, Berhame et al. 46 chamam a atenção para o fato de que as normas culturais usadas para manter o poder social dos homens e o senso de masculinidade dificultam a adoção de hábitos e convicções mais saudáveis. Assim, para os autores que tratam do poder associado à masculinidade, os homens, ao se sentirem fortes, resistentes e invulneráveis, podem não adotar comportamentos preventivos, nem tampouco acessar os serviços de saúde.

O terceiro núcleo de sentido associado ao poder masculino é o de homem como ser provedor. A discussão sobre esse assunto encontra-se presente, principalmente, em Stern et al. 22, Villaseñor-Farias \& Castañeda-Torres $43 \mathrm{e}$ Guerriero et al. 20.

Para Stern e al. 22, baseando-se em um estudo com adolescentes mexicanos, nem sempre a idéia de ser provedor, um dos elementos centrais do conceito de masculinidade, pode ser colocada em prática por alguns jovens por conta das condições econômicas em que vivem. Nesse sentido, ser provedor depende, em parte, de ter condições econômicas para tal.

Possuir condições econômicas, segundo Villaseñor-Farias \& Castañeda-Torres 43, é uma das formas de empoderamento masculino para adolescentes mexicanos. Assim, para esses sujeitos, a sua afirmação enquanto ser masculino passa pela necessidade de ter dinheiro.

Ainda na discussão relacionada a esse núcleo de sentido, encontra-se a valorização do homem como ser provedor para o campo da saúde pública. Tal valorização deve ser estimulada, segundo Guerriero et al. 20 , porque a idéia de ser um bom provedor para a família e ter responsabilidade podem contribuir para que homens adotem medidas preventivas. Ainda segundo os autores, tal idéia pode ser explorada tanto no sentido de incentivar o uso da camisinha quanto a não trazer doenças para casa, buscando, dentre outros aspectos, proteger uma gravidez fora do casamento.

\section{Considerações finais}

Tanto as fontes revisadas quanto a literatura que serviu de base para a realização deste estudo apontam para duas questões fundamentais sobre a relação homem-saúde: (a) modelos hegemônicos de masculinidade podem dificultar a adoção de hábitos e convicções mais saudáveis e (b) o homem, quando influenciado por ideologias hegemônicas de gênero, pode colocar em risco tanto a saúde da mulher quanto a sua própria.

A partir do diálogo entre as temáticas delineadas pela análise dos conteúdos dos artigos 
revisados e a literatura utilizada na introdução deste estudo, algumas considerações finais podem ser estabelecidas.

Em primeiro lugar, verificou-se que, na seção referente à saúde pública, na biblioteca eletrônica (http://www.scielo.org), o homem vem se consolidando como objeto de investigações de cunho predominantemente epidemiológicas. No entanto, cabe observar que essa abordagem não vem focalizando o ser masculino exclusivamente como uma variável de sexo em perfis de morbimortalidade. Já traz, ainda que pouco desenvolvida, uma discussão acerca das especificidades do adoecer masculino e do adoecer feminino por conta de questões das identidades masculinas. Essa constatação reforça o movimento que vem sendo feito, na literatura internacional, no sentido de focalizar a masculinidade dentro dos estudos de gênero e saúde.

Especificamente no que tange à temática sexualidade masculina, observou-se que os estudos, ao tratarem do exercício dessa sexualidade como campo propenso à transmissão de infecções, focalizaram mais as questões de doença do que as de saúde propriamente dita. Nesse cenário, a sexualidade apareceu muito mais como vilã do que como protagonista das relações saudáveis entre as pessoas. Isso, de certa forma, reforça a constatação da literatura introdutória de que há poucos estudos que buscam refletir sobre as questões de saúde no campo da sexualidade nas relações de gênero.

Ainda em relação à sexualidade masculina, verificou-se que ainda são necessários mais estudos sobre homossexualidade e heterossexualidade, independentemente do peso moral a elas atribuído, no sentido de avançar tanto na compreensão quanto na problematização desses aspectos da sexualidade para que medidas preventivas sejam promovidas.

No tema masculinidade e reprodução, observou-se que os autores revisados trazem, em suas discussões, idéias bem semelhantes às que se encontram na literatura que serviu para introduzir a presente revisão bibliográfica. Dentre essas idéias, destaca-se a de que as questões relacionadas à saúde reprodutiva devem ser desenvolvidas a partir de uma perspectiva relacional de gênero.

Apesar de já existir inúmeros estudos que advogam a participação dos homens na saúde reprodutiva, constatou-se a necessidade de ganhar-se maior densidade a partir de investigações que não só tragam o homem para o cenário do planejamento familiar como também consiga, numa perspectiva relacional de gênero, tratar de suas especificidades ligadas às questões reprodutivas. Assim como se tem a perspectiva de empoderamento das mulheres nas esferas decisórias, investimentos deverão ser promovidos para que os homens também se sintam sujeitos no campo reprodutivo.

Quanto ao tema masculinidade e poder, os artigos revisados e a literatura que serviu de apoio à introdução deste estudo coincidem no debate sobre as implicações da violência masculina cometida contra a mulher no campo da saúde pública. Nesses dois conjuntos de fontes, considera-se que o enfrentamento dessa violência constitui um grande desafio, porque envolve, dentre inúmeros fatores, a complexidade de lidar com questões culturais que podem reforçar tal violência. Para alguns contextos culturais, o homem tem poderes sobre as mulheres, e, quando tais poderes encontram impedimentos de se realizarem, o uso da violência contra a mulher pode ser justificável. Nesses contextos, os homens que praticam violência contra as mulheres, vistos na ótica dos serviços de saúde como autores de violência, podem ser percebidos como agente em exercício de defesa de direitos estabelecidos.

Ainda nas questões relacionadas ao poder associado à masculinidade, lacunas foram percebidas. Em geral, os estudos revisados constataram influências dessas questões tanto na promoção da saúde quanto na intervenção da doença. No entanto, estudos sob a dimensão sociocultural ainda se fazem necessários. Ancorada nas ciências sociais, a saúde pública poderá avançar na compreensão de que o homem, quando influenciado por ideologias hegemônicas de gênero, pode colocar em risco tanto a saúde da mulher quanto a sua própria. Assim a construção da masculinidade com marcas identitárias - como adoção do status quase que exclusivo de ser ativo, a crença de que deve expressar invencibilidade, a associação do masculino à necessidade de expor-se ao risco, a naturalização do descontrole sexual e a redução do exercício da sexualidade à penetração pode influenciar a não adoção de medidas de proteção contra doenças.

Com base nas ciências sociais, a área da saúde pública poderá avançar também na compreensão da possibilidade de aspectos normativo-sociais serem alterados ou ressignificados pela subjetividade dos atores sociais.

Essas idéias, em si, não são novidades. Ao contrário, nas discussões desenvolvidas por profissionais da saúde pública, são recorrentes. Entretanto, o conjunto da produção de artigos estudados aponta para o fato de que ainda há poucos estudos que dêem conta da sustentação dessas discussões. 
Por último, em termos de lacunas, pode-se destacar que pesquisas ainda se fazem necessárias para que sejam aprofundadas as relações entre masculinidades, no plural, e saúde. Nesse sentido, as investigações com abordagem

\section{Resumo}

O estudo tem como objetivo analisar a produção bibliográfica sobre a relação homem-saúde, no campo da saúde pública. A partir dessa análise, pretende-se problematizar as idéias mais recorrentes nas considerações sobre as especificidades do ser homem no processo saúde-doença. O método consistiu-se numa revisão bibliográfica de artigos de saúde pública, realizada a partir de uma abordagem de pesquisa qualitativa. Sexualidade masculina, masculinidade e reprodução e masculinidade e poder foram os temas encontrados na análise. Concluiu-se que ainda são necessárias investigações sobre as masculinidades relacionadas a gênero, nacionalidade, classe, idade, etnia e orientação sexual.

Saúde do Homem; Literatura de Revisão; Pesquisa Qualitativa

\section{Colaboradores}

R. Gomes e E. F. Nascimento participaram igualmente da pesquisa bibliográfica e da redação do artigo.

\section{Agradecimentos}

Os autores agradecem a Cicero Rogério da Silva Barros pela valiosa colaboração na organização dos dados da revisão bibliográfica. qualitativa podem trazer contribuições para que tais relações tornem-se mais visíveis a partir dos cenários de nacionalidade, classe, idade, raça/etnia e orientação sexual, dentre outros.

\section{Referências}

1. Courtenay WH. Constructions of masculinity and their influence on men's well-being: a theory of gender and health. Soc Sci Med 2000; 50:1385401.

2. Schraiber LB, Gomes R, Couto MT. Homens na pauta da saúde coletiva. Ciênc Saúde Coletiva 2005; 10:7-17.

3. World Health Organization. Boys in the picture. Geneva: World Health Organization; 2000.

4. World Health Organization. Men, ageing and health. Geneva: World Health Organization; 2001.

5. Introduction to the International Society for Men's and Gender (ISMH). Journal of Men's Health and Gender 2004; 1:8-11.

6. Luck M, Bamford M, Williamson P. Men's health: perspectives, diversity and paradox. London: Blackwell Sciences; 2000.

7. Sabo D. O estudo crítico das masculinidades. In. Adelman M, Silvestrin CB, organizadoras. Coletânea gênero plural. Curitiba: Editora UFPR; 2002. p. 33-46.

8. Keijzer B. Hasta donde el cuerpo aguante: género, cuerpo y salud masculina. In: Cáceres C, Cueto M, Ramos M, Vallens S, organizadores. La salud como derecho ciudadano: perspectivas y propuestas desde América Latina. Lima: Facultad de Salud Pública y Administración, Universidad Peruana Cayetano Heredia; 2003. p. 137-52.

9. Bardin L. Análise de conteúdo. Lisboa: Edições $70 ; 1979$

10. Gomes R. A análise de dados em pesquisa qualitativa. In: Minayo MCS, organizadora. Pesquisa social: teoria, método e criatividade. Petrópolis: Editora Vozes; 2002. p. 67-80.

11. Leyva-Lopez AG, Aranda-Flores CE, Conde-González C, Lazcano-Ponce EC. La baja utilidad de la determinación del ADN del VPH en la región distal de la uretra masculina. Salud Pública Méx 2003; 45 Suppl 5:S589-93.

12. Pépin J, Sobéla F, Deslandes S, Alary M, Wegner K, Khonder N, et al. Etiology of urethral discharge in West Africa: the role of mycoplasma genitalium and trichomonas vaginales. Bull World Health Organ 2001; 79:118-26.

13. Monteiro CA, Moura EC, Conde WL, Popkin BM. Socioeconomic status and obesity in adult population of developing: a review. Bull World Health Organ 2004; 82:940-6.

14. O'Farrell N. Targeted interventions required against genital ulcers in African countries worst affected by HIV infection. Bull World Health Organ 2001; 79:569-77.

15. Castellsagué X, Bosch FX, Muñoz MD. The male role in cervical cancer. Salud Pública Méx 2003; 45 Suppl 3:S345-53. 
16. Espírito-Santo MEG, Etheredge GD. How to reach clients of female sex worker: a survey 'by surprise' in Dakar, Senegal. Bull World Health Organ 2002; 80:709-13.

17. Hawkes S, Morison L, Chakraborty J, Gausia K, Ahmed F, Islam SF, et al. Reproductive tract infections: prevalence and risk factors in rural Bangladesh. Bull World Health Organ 2002; 80:180-8.

18. Nieto-Andrade B, Izazola-Licea JA. Uso del condón en hombres con parejas no estable en la ciudad de México. Salud Pública Méx 1999; 41:85-94.

19. Secretaría del Plan Nacional sobre Sida/Programas de Sida de las Comunidades Autônomas/Red de Centros de Enfermedades de transmisión Sexual, VIH y Planificación Familiar. Seroprelalencia de VIH em las personas que acuden a consultas de enfermedades de transmisión sexual y planificación familiar. España, 1995-1996. Rev Esp Salud Pública 1999; 73:25-34.

20. Guerriero I, Ayres JRCM, Hearst N. Masculinidade e vulnerabilidade ao HIV de homens heterossexuais. Rev Saúde Pública 2002; 36:50-60.

21. Rios LF. Parcerias e práticas sexuais de jovens homossexuais no Rio de Janeiro. Cad Saúde Pública 2003; 19 Suppl 2:S223-32.

22. Stern C, Fuentes-Zurita C, Lozano-Treviño LR, Reysoo F. Masculinidade, saúde sexual e reprodutiva: um estudo de caso com adolescentes da Cidade do México. Salud Pública Méx 2003; 45 Suppl 1:S34-43.

23. Burattini MN, Massad E, Rozman M, Azevedo RS, Carvalho HB. Correlação entre HIV e HCV em prisioneiros brasileiros: evidência de transmissão parenteral no encarceramento. Rev Saúde Pública $2000 ; 34: 431-6$

24. Izazola-Licea JA, Gortmaker SL, Gruttola V, Tolbert $\mathrm{K}$, Mann J. Assessment of non-response bias in a probability household survey of male same-gender sexual behavior. Salud Pública Méx 2000; 42:90-8.

25. Figueroa-Perea JG. Alguns elementos para interpretar a presença dos homens nos processos de saúde reprodutiva. Cad Saúde Pública 1998; 14 : 87-96.

26. Funari SL. Sexo oral e HIV entre homens que fazem sexo com homens. Cad Saúde Pública 2003; 19:1841-4.

27. Viliet CV, Meester EI, Korenromp EL, Singer B, Bakker R. Focusing strategies of condom use against HIV in different behavioral settings: an evaluation based on a simulation model. Bull World Health Organ 2001; 79:442-54.

28. Mariño R, Minichiello V, Disogra C. Male sex workers in Córdoba, Argentina: sociodemographic characteristics and sex work experiences. Pan Am J Public Health 2003; 13:311-9.

29. Silva CGM. O significado de fidelidade e as estratégias para prevenção da Aids entre homens casados. Rev Saúde Pública 2002; 36 (4 Suppl):40-9.

30. Cañellas S, de La Paz JP, Noguer I, Villamil F, Berrocal MLG, Fuente L, et al. Conductas sexuales de riesgo y prevalecía de infección por VIH en hombres con prácticas homosexuales y bisexuales en la comunidad de Madrid. Rev Esp Salud Pública 2000; 74:25-32.

31. Hernández-Girón C, Cruz-Valdez A, Quiterio-Trenado M, Peruga A, Hernández-Avila M. Carac- terísticas de comportamiento sexual en hombres de la ciudad de México. Salud Pública Méx 1999; 41:95-100.

32. Villarinho L, Bezerra I, Lacerda R, Latorre MRDO, Paiva V, Stall R, et al. Caminhoneiros de rota curta e sua vulnerabilidade ao HIV. Rev Saúde Pública 2002; 36:61-7.

33. Vieira EM, Vilela WV, Réa MF, Fernandes MEL, Franco E, Ribeiro G. Alguns aspectos do comportamento sexual e prática de sexo seguro em homens do Município de São Paulo. Cad Saúde Pública 2000; 16:997-1009.

34. Viveros M, Gomes F, Otero E. Las representaciones sociales sobre la esterilización masculina. El punto de vista de los orientadores del servicio de vasectomía en la Clínica del Hombre, en Bogotá, Colombia. Cad Saúde Pública 1998; 14 Suppl 1:97-103.

35. Antunes MC, Peres CA, Paiva V, Stall R, Hearst N. Diferenças na prevenção da Aids entre homens e mulheres jovens de escolas públicas em São Paulo. Rev Saúde Pública 2002; 36:88-95.

36. Cruz-Peñarán D, Langer-Glas A, Hernández-Prado B, González-Rengijo GF. Conocimientos y actitudes de la paneja hacia la práctica de la planificación familiar en la Selva del Perú. Salud Pública Méx 2003; 45:461-71.

37. Carvalho MLO, Pirotta KCM, Schor N. Participação masculina na contracepção pela ótica feminina. Rev Saúde Pública 2001; 35:23-31.

38. Duarte GA, Alvarenga AT, Osis MJMD, Faúndes A, Hardy E. Perspectiva masculina acerca do aborto provocado. Rev Saúde Pública 2002; 36:271-7.

39. Golden AL, Moline JM, Bar-Chama N. Male reproduction and environmental and occupational exposures: a review of epidemiologic methods. Salud Pública Méx 1999; 41 Suppl 2:S93-105.

40. Multigner L, Oliva A. Secular variations in sperm quality: fact or science fiction? Cad Saúde Pública 2002; 18:403-12.

41. Rittler M, Castilla EE. Endocrine disruptors and congenital anomalies. Cad Saúde Pública 2002; 18:424-8.

42. Jarrel J. Rationale for the study of the human sex ratio in population studies of polluted environments. Cad Saúde Pública 2002; 18:429-34.

43. Villaseñor-Farias M, Castañeda-Torres J. Masculinidad, sexualidad, poder y violencia: análisis de significados en adolescentes. Salud Pública Méx 2003; 45 Suppl 1:S44-57.

44. Hindin MJ. Understanding women's attitudes towards wife beating in Zimbabwe. Bull World Health Organ 2003; 81:501-8.

45. Abrahams N, Jewkes R, Hoffman M, Laubsher R. Sexual violence against intimate partners in Cape Town: prevalence and risk factors reported by men. Bull World Health Organ 2004; 82:330-7.

46. Berhame Y, Högberg U, Byass P, Wall S. Gender, literacy, and survival among Ethiopian adults. Bull World Health Organ 2002; 80:714-20.

Recebido em 17/Jun/2005

Versão final reapresentada em 04/Out/2005

Aprovado em 10/Out/2005 